\title{
Fisioter Bras 2021;22(1):86-101
}

Tabela I - Resultados obtidos em relação aos métodos de avaliação, grupo de intervenção, frequência, intensidade, duração e principais conclusões

\begin{tabular}{|c|c|c|c|c|c|c|}
\hline $\begin{array}{l}\text { Autor/ } \\
\text { ano/ País }\end{array}$ & Objetivo & $\begin{array}{l}\text { Métodos de } \\
\text { avaliação }\end{array}$ & $\begin{array}{l}\text { Grupos de } \\
\text { Intervenção }\end{array}$ & $\begin{array}{l}\text { Frequência/ Intensidade/ } \\
\text { Duração }\end{array}$ & Conclusão & DB \\
\hline $\begin{array}{l}\text { Kymplová } \\
\text { et al. } 2003 \\
\text { [19] } \\
\text { República } \\
\text { Tcheca }\end{array}$ & $\begin{array}{l}\text { Avaliar os } \\
\text { benefícios } \\
\text { da } \\
\text { fototerapia } \\
\text { implementa } \\
\text { da com } \\
\text { laser } \\
\text { terapêutico } \\
\text { ou luz } \\
\text { polarizada } \\
\text { no } \\
\text { tratamento } \\
\text { da } \\
\text { episiotomia. }\end{array}$ & $\begin{array}{l}\text { Avaliação: } \\
\text { N/l. } \\
\text { Método: N/I. }\end{array}$ & $\begin{array}{l}\text { Total: } \\
\mathrm{n}=2.436 \\
\text { Grupos: } \\
\text { GK (controle): } \\
\mathrm{n}=592 \\
\text { GA: LBP } \\
\mathrm{n}=748 \\
\text { GB: Luz } \\
\text { Polarizada } \\
\mathrm{n}=581 \\
\text { GC: Luz } \\
\text { polarizada } \\
\text { magnetizada } \\
\mathrm{n}=715\end{array}$ & $\begin{array}{l}\text { Frequência: } 1 \times \text { ao dia } \\
\text { - } 4 \text { sessões (em média) } \\
\text { Intensidade: } \\
\text { - LBP: } 2 \mathrm{~J} / \mathrm{cm}^{2}, 670 \mathrm{~nm} \text {, } \\
\text { potência } 20 \mathrm{~mW}, \mathrm{f}=10 \mathrm{~Hz}, 25 \mathrm{e} \\
50 \mathrm{~Hz} \text {, duração: } \mathrm{N} / \mathrm{l} . \\
\text { - Luz polarizada: } 5 \mathrm{~J} / \mathrm{cm}^{2}, 400- \\
2.000 \mathrm{~nm} \text {, potência } 40 \mathrm{~mW}, \\
\text { duração: } \mathrm{N} / \mathrm{l} \text {. } \\
\text { - Luz polarizada magnetizada: } \\
0,5 \mathrm{~J} / \mathrm{cm}^{2}, 660 \mathrm{~nm} \text {, potência } \\
40 \mathrm{~mW} \text {, frequência } 1 \mathrm{~Hz} \text {, indução } \\
\text { magnética } 8 \mathrm{Mt} \text {, duração: } 3 \text { min. } \\
\text { Duração: Aplicações durante o } \\
\text { período de hospitalização (4- } 6 \\
\text { dias). }\end{array}$ & $\begin{array}{l}\text { - A fototerapia reduziu complicações } \\
\text { significativamente ( } p<0,01) \text {. Todas as } \\
\text { intervenções apresentaram redução na } \\
\text { ocorrência de complicações na } \\
\text { cicatrização, sendo o LBP com melhor } \\
\text { desempenho. } \\
\text { - O grupo A apresentou } 2 \text { casos de } \\
\text { complicações na cicatriz de episiotomia } \\
\text { (hiperemia), o grupo B apresentou } 3 \\
\text { complicações (deiscência parcial e } \\
\text { hiperemia). No grupo C, } 8 \text { complicações } \\
\text { foram observadas ( } 3 \text { casos de deiscência } \\
\text { completa, } 3 \text { casos de deiscência parcial e } \\
2 \text { casos de hiperemia), no grupo K foram } \\
\text { observadas } 58 \text { complicações na } \\
\text { episiotomia (deiscência completa com } \\
\text { ressutura, deiscência subcutânea e } \\
\text { cutânea com secreção mucopurulenta). }\end{array}$ & $37 \%$ \\
\hline $\begin{array}{l}\text { Santos } \\
\text { et al. } \\
2011 \text { [20] } \\
\text { Brasil }\end{array}$ & $\begin{array}{l}\text { Avaliar os } \\
\text { efeitos da } \\
\text { laserterapia } \\
\text { de baixa } \\
\text { potência na } \\
\text { dor e } \\
\text { cicatrização } \\
\text { perineal } \\
\text { após } \\
\text { episiotomia. }\end{array}$ & $\begin{array}{l}\text { Avaliação: } \\
\text { - Escala de } \\
\text { dor (0 a 10) } \\
\text { - Escala } \\
\text { REEDA } \\
\text { Método: } \\
\text { Avaliações de } \\
\text { dor pré e pós } \\
\text { sessão; escala } \\
\text { REEDA pré e } \\
\text { após } 15 \text { a } 20\end{array}$ & $\begin{array}{l}\text { Total: } \\
\mathrm{n}=52 \\
\text { Grupos: } \\
\text { GC: LBP placebo } \\
\mathrm{n}=26 \\
\text { GE: LBP } \\
\mathrm{n}=26\end{array}$ & $\begin{array}{l}\text { Frequência: } \\
1^{\circ} \text { sessão imediatamente após } \\
\text { a sutura ou em até } 2 \mathrm{~h} \text { após } 0 \\
\text { parto. } \\
2^{\circ} \text { sessão entre } 20 \text { e } 24 \mathrm{~h} \text { após o } \\
\text { parto } \\
3^{\circ} \text { sessão entre } 40 \text { e } 48 \mathrm{~h} \text { após o } \\
\text { parto. } \\
\text { Aplicação realizada em } 3 \text { pontos } \\
\text { da episiotomia (extremidades e } \\
\text { ponto médio). } \\
\text { Intensidade: }\end{array}$ & $\begin{array}{l}\text { - Ocorreu diminuição de dor em ambos } \\
\text { grupos após a irradiação. O GE } \\
\text { apresentou variação de escores médios } \\
\text { de dor após } 2^{\mathrm{a}} \text {. e } 3^{\mathrm{a}} \text {. sessão ( } \mathrm{p} 1 / 40,003 \text { e } \\
\text { p0,001, respectivamente) e no GC } \\
\text { ocorreu diminuição de dor significativa } \\
\text { após a } 1^{\circ} \text { aplicação. Houve redução de } \\
\text { dor intragrupo nos dois grupos, no } \\
\text { entanto, não foram observadas diferenças } \\
\text { significativas ao comparar os escores } \\
\text { médios de dor perineal entre os grupos } \\
\text { em cada uma das três. O LBP não }\end{array}$ & $96 \%$ \\
\hline
\end{tabular}




\begin{tabular}{|c|c|c|c|c|c|c|}
\hline & & $\begin{array}{l}\text { dias a última } \\
\text { sessão. }\end{array}$ & & $\begin{array}{l}\text { Dose } 3,8 \mathrm{~J} / \mathrm{cm}^{2}, 660 \mathrm{~nm} \text {, } \\
\text { potência } 15 \mathrm{~mW}, 10 \mathrm{~s} \text { em cada } \\
\text { ponto, totalizando } 30 \mathrm{~s} \text { de } \\
\text { aplicação. }\end{array}$ & $\begin{array}{l}\text { acelerou o processo cicatricial. Não } \\
\text { houve diferenças significativas em } \\
\text { nenhuma das } 4 \text { avaliações. Embora os } \\
\text { escores médios de dor perineal do GE } \\
\text { tenham sido menores, não é possível } \\
\text { afirmar que o LBP teve papel na redução } \\
\text { da dor perineal. }\end{array}$ & \\
\hline $\begin{array}{l}\text { Santos } \\
\text { et al. } \\
2012 \text { [21] } \\
\text { Brasil }\end{array}$ & $\begin{array}{l}\text { Avaliar a } \\
\text { eficácia dos } \\
\text { efeitos do } \\
\text { LBP para } \\
\text { alívio dor } \\
\text { perineal } \\
\text { após } \\
\text { episiotomia. }\end{array}$ & $\begin{array}{l}\text { Avaliação: } \\
\text { - Escala de } \\
\text { dor (0 a 10) } \\
\text { Método: } \\
\text { Avaliação } \\
\text { realizada } \\
\text { antes, } \\
\text { imediatamente } \\
\text { depois e } 30 \\
\text { min após a } \\
\text { sessão de } \\
\text { aplicação de } \\
\text { LBP. }\end{array}$ & $\begin{array}{l}\text { Total: } \\
\mathrm{n}=114 \\
\text { Grupos: } \\
\text { GC: } \mathrm{n}=38 \\
\text { GE(IV) } \\
\text { Infravermelho: } \mathrm{n}= \\
38 \\
\text { GE (LBP) } \mathrm{n}=38\end{array}$ & $\begin{array}{l}\text { Frequência: } \\
\text { - } 1 \text { única sessão. } \\
\text { Intensidade: } \\
\text { - Laser infravermelho: Dose } 8 \\
\mathrm{~J} / \mathrm{cm}^{2}, 780 \mathrm{~nm} \text {, potência } 35 \mathrm{~mW} \text {, } \\
30 \text { s de aplicação. } \\
\text { - LBP: Dose } 8 \mathrm{~J} / \mathrm{cm}^{2}, 660 \mathrm{~nm} \text {, } \\
\text { potência } 35 \mathrm{~mW}, 30 \mathrm{~s} \text { de } \\
\text { aplicação. }\end{array}$ & $\begin{array}{l}\text { - Houve reduções significativas nos } \\
\text { escores médios de dor nas comparações } \\
\text { intragrupos imediatamente após a } \\
\text { irradiação e } 30 \text { min após o tratamento nos } \\
\text { três grupos. } \\
\text { - No entanto, ao comparar os escores } \\
\text { médios de dor perineal entre os } 3 \text { grupos } \\
\text { nas etapas de avaliação não houve } \\
\text { diferenças estatisticamente significativas } \\
\text { imediatamente }(p=0,234) \text { ou } 30 \text { min após } \\
\text { a irradiação }(p=0,111) \text {. }\end{array}$ & $93 \%$ \\
\hline $\begin{array}{l}\text { Chougala } \\
\text { et al. } \\
2015 \text { [22] } \\
\text { Índia }\end{array}$ & $\begin{array}{l}\text { Avaliar a } \\
\text { eficácia do } \\
\text { ultrassom } \\
\text { terapêutico } \\
\text { e da } \\
\text { laserterapia } \\
\text { de baixo } \\
\text { nível para } \\
\text { dor perineal } \\
\text { após o } \\
\text { parto } \\
\text { vaginal com } \\
\text { episiotomia. }\end{array}$ & $\begin{array}{l}\text { Avaliação: } \\
\text { - Escala visual } \\
\text { analógica } \\
\text { (EVA) } \\
\text { - Escala } \\
\text { REEDA } \\
\text { Método: } \\
\text { Avaliação } \\
\text { realizada no } \\
\text { primeiro dia } \\
\text { antes da } \\
\text { intervenção e } \\
\text { no terceiro dia } \\
\text { após a } \\
\text { intervenção. }\end{array}$ & $\begin{array}{l}\text { Total: } \\
n=60 \\
\text { Grupos: } \\
\text { GE(A) } \\
\text { (Ultrassom): } \\
n=30 \\
\text { GE(B) (LBP): } \\
n=30\end{array}$ & $\begin{array}{l}\text { Frequência: } \\
\text { - } 1 x \text { ao dia } \\
\text { - } 3 \text { dias consecutivos após o } \\
\text { parto. } \\
\text { Intensidade: } \\
\text { - Ultrassom terapêutico: } \\
\text { Intensidade } 3 \mathrm{MHz}, 0,5 \mathrm{w} / \mathrm{cm}^{2} \\
\text { com intervalo de pulso } 1: 1 \\
\text { durante } 5 \text { minutos. } \\
\text { - LBP: Dose } 3,8 \mathrm{~J} / \mathrm{cm}^{2}, \\
660 \text { nm, potência } 15 \mathrm{~mW} \\
\text { durante } 30 \mathrm{~s} \text {. }\end{array}$ & $\begin{array}{l}\text { - Ambos grupos apresentaram redução } \\
\text { estatisticamente significativa de dor no } \\
\text { terceiro dia após a intervenção, } p<0,001 \text {, } \\
\text { com maior redução no grupo A em } \\
\text { comparação ao grupo B. } \\
\text { - Ambos grupos apresentaram melhora } \\
\text { estatisticamente significativa na escala } \\
\text { REEDA no terceiro dia após a } \\
\text { intervenção, } \\
\text { p <0,001, com maior redução no grupo A } \\
\text { em comparação ao grupo B. }\end{array}$ & $23 \%$ \\
\hline
\end{tabular}




\begin{tabular}{|c|c|c|c|c|c|c|}
\hline $\begin{array}{l}\text { Alvarenga } \\
\text { et al. } \\
2016 \text { [23] } \\
\text { Brasil }\end{array}$ & $\begin{array}{l}\text { Avaliar os } \\
\text { efeitos da } \\
\text { laserterapia } \\
\text { de baixo } \\
\text { nível na dor } \\
\text { e } \\
\text { cicatrização } \\
\text { perineal } \\
\text { após } \\
\text { episiotomia. }\end{array}$ & $\begin{array}{l}\text { Avaliação: } \\
\text { - Escala de } \\
\text { dor (0 a 10) } \\
\text { - Escala } \\
\text { REEDA } \\
\text { Método: } \\
\text { Avaliações } \\
\text { realizadas } \\
\text { antes, } \\
\text { imediatamente } \\
\text { após e } 30 \text { min } \\
\text { após cada } \\
\text { sessão e } \\
\text { escala REEDA } \\
\text { reaplicada } \\
\text { entre } 15 \text { e } 20 \\
\text { dias a última } \\
\text { sessão. }\end{array}$ & $\begin{array}{l}\text { Total: } \\
n=54 \\
\text { Grupos: } \\
\text { GE: LBP } \\
n=25 \\
\text { GC: LBP placebo } \\
n=29\end{array}$ & $\begin{array}{l}\text { Frequência: } \\
1^{\text {a }} \text {. sessão: } \\
\text { realizada entre } 6 \text { e } 10 \mathrm{~h} \text { após o } \\
\text { parto. } \\
2^{\mathrm{a}} \text {. sessão: } \\
\text { realizada entre } 20 \text { e } 24 \mathrm{~h} \text { após o } \\
\text { parto } \\
3^{\circ} \text { sessão: } \\
\text { realizada entre } 40 \text { e } 48 \mathrm{~h} \text { após o } \\
\text { parto. }\end{array}$ & 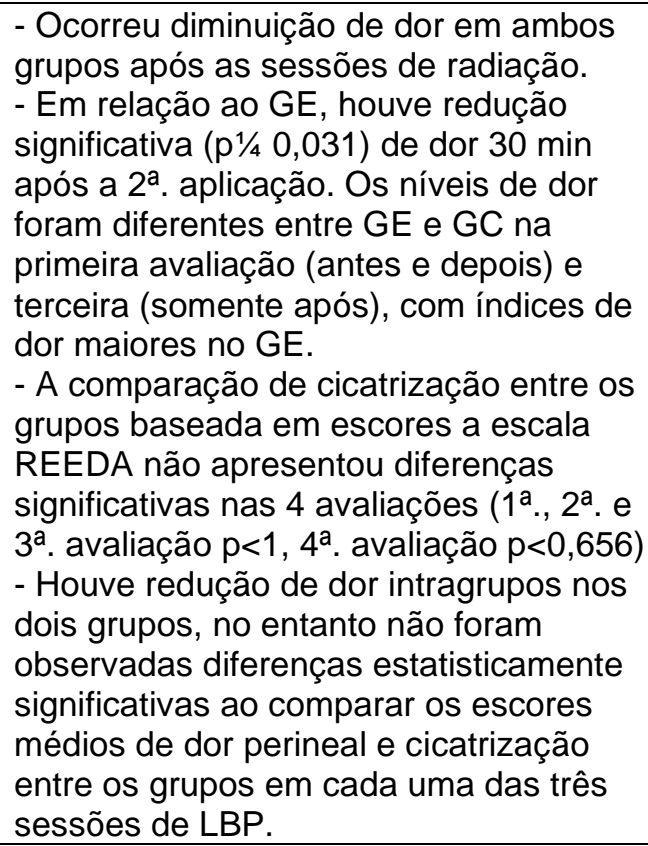 & $\begin{array}{l}100 \\
\%\end{array}$ \\
\hline
\end{tabular}

$\mathrm{DB}=$ Check list Downs and Black; N/I = não informado; GC = Grupo controle; GE = Grupo experimental; LBP = laser de baixa potência; EVA = escala visual analógica; Escala REEDA = hiperemia, edema, equimoses, aproximação de bordas de pele da ferida 